\title{
Los caballos y las Órdenes de Caballería: una visión a través de Las Siete Partidas de Alfonso X, "El Sabio", $y$ de otros documentos
}

\author{
Martínez Pérez JM. ${ }^{1}$, Martínez Pérez JÁ. ${ }^{2}$, Domínguez Sánchez S. ${ }^{3}$, Martínez Rodríguez JM. ${ }^{4}$ \\ Sanid. mil. 2014; 70 (4): 309-317; ISSN: 1887-8571
}

\begin{abstract}
RESUMEN
El código de honor que regía la vida del caballero medieval fue una conquista relativamente tardía -durante el S. XII, aproximadamente-, lograda principalmente por la Iglesia para controlar los desmanes de los primitivos guerreros. Los cambios sociales y culturales acentuaron la evolución. Para este estudio, se han utilizado documentos del S. XIII donde se observa la importancia de los Caballos Hispanos de la época, especialmente por su uso bélico contra los musulmanes. Además, se ha extraído la información más interesante dentro de Las Siete Partidas de Alfonso X, "El Sabio", donde se muestra la visión que se tenía de los caballeros y sus armas (siendo el caballo el arma ideal) durante la Baja Edad Media. Todos estos documentos son esenciales para comprender este periodo histórico y la evolución posterior, con la unión de las coronas peninsulares y la formación de un Ejército único para toda España, con la Caballería como eje.
\end{abstract}

\section{PALABRAS CLAVE: Orden Militar, Caballo, Cruzadas, Alfonso X, Siete Partidas.}

The horses and the Orders of Chivalry: a vision through "The Seven-Part Code" of Alfonso XI "The Wise" and other documents SUMMARY: The honor code followed by the medieval knight was a relatively late achievement -during the $12^{\text {th }}$ century, approximately-, mainly thanks to the Church in order to control the abuses of primitive warriors. Social and cultural changes increased evolution. For this work, some documents from the $13^{\text {th }}$ century have been used, which show the importance of Hispanic Horses of that time, in special for their military services against muslims. Besides, the most interesting information from The Seven-Part Code of Alfonso X, "The Wise", has been extracted and it shows how the knights and their weapons (the ideal weapon the horse) were considerated during the Middle Ages. All these documents are essential to understanding this historical epoch and the next period, with the union of peninsular crowns and the consolidation of a unique Army for Spain, with the Cavalry as a central axis.

KEY WORDS: Military Order, Horse, Crusades, Alfonso X, The Seven-Part Code.

\section{INTRODUCCIÓN}

La Edad Media europea se extiende desde el S. V (476) al S. XV (1453). Los SS. XI y XII son siglos duros enmarcados por la actividad guerrera, y suavizados por los valores épicos que encarnan los nobles y caballeros rudos. Las ilustraciones y miniaturas de la época nos muestran un mundo de colores, belleza y fantasía digno de las novelas de caballería.

Para entroncar el espíritu caballeresco de las novelas de caballerías, sólo unas pinceladas para reflejar su exuberante floración que excede con mucho al de otros géneros literarios juntos en toda la Edad Media y siglos posteriores. Aunque nacieron de la épica medieval, ofrecen características diferentes hasta la época

\footnotetext{
${ }^{1}$ Doctor en Veterinaria. Universidad de León. Dpto. de Sanidad Animal (Parasitología y Enfermedades Parasitarias). Facultad de Veterinaria. España.

2 Tte. Artillería. RAMIX-30. Doctor en Historia. Ceuta. España.

${ }^{3}$ Doctor en Historia. Catedrático de la Universidad de León. Dpto. de Patrimonio Artístico y Documental. Facultad de Filosofía y Letras. España.

${ }^{4}$ Doctor en Veterinaria. Profesor Titular de la Universidad de León. Dpto. de Medicina, Cirugía y Anatomía Veterinaria. Facultad de Veterinaria. España.

Dirección para correspondencia: José Manuel Martínez Pérez. Facultad de Veterinaria de León. Departamento de Sanidad Animal (Área de Parasitología y Enfermedades Parasitaria). Campus de Vegazana s/n. 24071 León. Correo electrónico:jmarp@unileon.es

Recibido: 30 de julio de 2013

Aceptado: 23 de diciembre de 2013
}

del Quijote. Entre las bondades caballerescas reflejadas en todas estas manifestaciones, figuran el amor a una dama, el código de honor que regía el comportamiento del caballero de la Edad Media -dentro del cual estaba la obligación de ayudar y defender al humilde y oprimido-, o el heroísmo individual que el héroe prodiga en aventuras y hazañas fantásticas realizadas en nombre de la dama reverenciada.

La Reconquista fue larga y dura, siempre alerta a las invasiones africanas (Almorávides, Almohades). Los acontecimientos guerreros y heroicos ocurridos en la sociedad medieval nos han llegado a través de los cantares de gesta y otras manifestaciones literarias, amén de la transmisión oral. El vehículo de transmisión de hazañas y gestas era la lengua romance, que servía para llevar al pueblo las informaciones y leyendas que conformaban el mundo medieval. Pero la prosa escrita pertenecía al mundo social alfabetizado y con este dato nos introducimos en la época de Alfonso X, "El Sabio", eslabón determinante para la evolución de la cultura castellana. La gloria del monarca resulta oscurecida por las vicisitudes políticas. Su talante hubiera encajado mejor en una época de monarquía más institucionalizada y menos complicada por los díscolos nobles ${ }^{1}$. En cualquier caso, la labor de Alfonso X parte de una lúcida voluntad política donde ya se vislumbra la idea del Estado e incluso la de Nación. La voluntad de hacer del castellano el idioma de la calle, también el vehículo de la Cultura y de la Historia figura implícitamente en Las Siete Partidas como 
propósito y objetivo didáctico de promover las élites castellanas. El Rey Sabio considera que la Corte ha de ser la escuela de los hombres corteses: “... llamáronlos corteses porque las bondades y los otros enseñamientos buenos a que llaman cortesía siempre los hallaron y los aprisieron en las cortes...". La magnitud de su obra completa y los resultados obtenidos hacen que sea considerado iniciador del pensamiento humanístico español.

Nosotros nos centramos en su obra jurídica Las Siete Parti$d a s^{2}$. Es una recopilación excelente del mundo medieval. Abarca todos los aspectos de la actividad humana y viene a ser una especie de código civil que trata de imponer una ley justa fundamentada en las relaciones humanas. Se observan normas y reglas que rigen el comportamiento de los poderosos hasta las "penas y escarmientos" de los malhechores. Al principio, este cuerpo legal se tituló Libro de las leyes o Fuero de las leyes. Debió redactarse en Sevilla, residencia oficial de la Corte, y no fue sancionado hasta el siglo siguiente con Alfonso XI. Alfonso X, influido por el sentido esotérico del número siete, tan característico de la Edad Media, considera las Siete Partidas o partes del derecho, y hasta aparece en detalles curiosos, como al señalar las virtudes de las leyes: "Las leyes han de ser en siete maneras: creer, ordenar las cosas, mandar, ayuntar, galardonar, vedar y escarmentar." Siete son también las letras de "Alfonso" que, por cierto, se corresponden con las iniciales del prólogo de cada Partida. Aparte del valor jurídico, nos ofrecen un valor informativo, desplegando ante nosotros una amplia divulgación del mundo costumbrista de la época ${ }^{3}$.

Como fuentes, el monarca se basó en el derecho romano, en ideas de Aristóteles, de Séneca, de San Isidoro, juristas medievales de la "Escuela de Bolonia" (como Azón). A su vez, el Rey pretende que sirva de inspiración a legislaciones venideras. Alfonso $\mathrm{X}$ tuvo virtudes y defectos, el mayor de éstos, su bondad congénita que le llevó muchas veces a un terreno de blandura y de extrema generosidad, casi siempre censurable en un monarca; sus máximas virtudes, el amor al saber del que nos dejó tan vivas muestras, y el espíritu de justicia que le llevó a defender en todas partes lo que juzgaba su derecho, aunque en esta defensa no le acompañara la fortuna.

\section{LAS CRUZADAS - LA RECONQUISTA}

La relevancia de las Cruzadas es un hecho evidente al analizar la evolución de los ejércitos europeos y, más concretamente, su caballería. Muchas de las Órdenes Militares nacieron a la par durante los SS. XII y XIII, siendo en España fundamentales para el avance de la Reconquista ${ }^{4}$. Aunque las Cruzadas surgieron para recuperar los Santos Lugares en manos de los musulmanes, en la Península Ibérica la Reconquista tuvo rango de Cruzada, especialmente durante la Batalla de las Navas de Tolosa (1212) y la toma de Granada (1482-1492).

La Cruzadas comenzaron en el año 1095, siendo la última estrictamente en 1270. El principal impulsor de este tipo de expediciones militares fue el Papado. El origen de las mismas podría ser como consecuencia, por un lado, de la destrucción del Santo Sepulcro de Jerusalén en 1009, por parte del califa Alháquem, y por otro de la persecución hacia peregrinos y cristianos desde el S. XI a manos de los turcos selyúcidas. Tras varios intentos Jerusalén fue reconquistado en el año 1099. En todas ellas parti- ciparon fundamentalmente franceses, pero también cristianos de muchos otros reinos, entre ellos de los reinos hispanos de Aragón, Navarra, León y Castilla 5 .

Si hay algún concepto que tenga especial relación con las Cruzadas, ése es el de Orden Militar. En sus inicios eran congregaciones de clérigos que seguían las Reglas de Cluny y del Císter, aunque con la particularidad de ser, a su vez, caballeros cuya misión principal era la guerra contra los musulmanes. Podían tener un origen privado, pero siempre estaban bajo los auspicios de la Santa Sede. De sobra se conoce la importancia que tuvieron las Órdenes Militares en la conquista y mantenimiento de los Santos Lugares y en la asistencia a los peregrinos que visitaban Jerusalén. Entre ellas destacan en Europa la del Hospital de San Juan de Jerusalén y la del Temple. La primera fue fundada por caballeros franceses tras la toma de Jerusalén del año 1099; pronto se volvió una Orden compuesta por soldados de origen noble comprometidos a continuar la guerra a los infieles. La segunda, denominada Orden del Temple o Templarios (este nombre proviene del palacio del Temple que les fue donado en parte por el rey Balduino y que estaba sito en el antiguo solar del Templo de Salomón), fue constituida en el año 1118, con el fin de escoltar a los peregrinos que hacían la ruta hacia Tierra Santa ${ }^{6}$.

En la Península Ibérica surgieron a partir de estas dos ya mencionadas muchas Órdenes Militares, aunque las que tuvieron más importancia fueron las de Calatrava, la de Santiago, la de Montesa y la de Alcántara. La primera data del año 1158 y, como su propio nombre indica, fue fundada en la villa de Calatrava (Reino de Castilla) influenciada principalmente por la Orden del Temple. La Orden de Santiago ("Hermanos de Cáceres") nació en 1170 en el Reino de León y está considerada como la más importante que existió en la Península Ibérica; su creación tuvo un influjo importante por parte de la de Calatrava, aunque la de Santiago surgió con una vertiente militar y luego religiosa, siendo la primera opción la más importante. La Orden de Alcántara apareció en 1176 también en el Reino de León, siendo sus principios fundacionales similares a los de las Órdenes del Hospital y del Temple y, a diferencia de la anterior, su margen de actuación estaba muy restringido a la actual Extremadura. Estas tres Órdenes Militares Hispanas colaboraron completamente durante la Reconquista. La última y no menos importante fue la Orden de Montesa, cuya creación tuvo lugar en el Reino de Aragón en 1317, heredando el legado que dejaron los Caballeros de la Orden del Temple?.

No debemos olvidar que en la Península Ibérica existieron otras Órdenes Militares de carácter autóctono, aunque de menor calado, como las de Montjoie (1173), de Santa María de España (1270) y de la Banda (1332) en Castilla, las de la Militia Christi o Caesaraugustana (1122), la del Hacha (1149) y de San Jorge de Alfama (1201) en Aragón o las de Avis (1170) y de Cristo (1319) en Portugal. Así como el Reino de Navarra, donde se gestaron las primeras Órdenes Militares Hispanas, por no decir las primeras del mundo, como son la de la Encina (870), la de la Jarra o de la Terraza (1040) y la de San Salvador de Monreal (1128), más adelante la del Lebrel Blanco (1398). Su fundación podía ser en un principio de índole religiosa, pero no pasaría mucho tiempo hasta convertirse en una perfecta jerarquía militarizada, de hecho Órdenes Militares como la de Santiago tenían ya desde sus inicios carácter militar. De esta manera el jefe supremo era el gran maestre, y las más altas autoridades de los conventos y fortalezas eran 


\section{Los caballos y las Órdenes de Caballería: una visión a través de Las Siete Partidas de Alfonso X...}

los comendadores o los alcaides nombrados a su vez por ellos ${ }^{8}$. En un principio también tuvo cierta relevancia la figura del alférez. La manera de reclutar se regía por encomiendas que poseían una cantidad determinada de hombres y caballos, administradas también por un comendador.

Normalmente cubriendo la armadura de caballero se solía llevar un manto, dependiendo su color de la Orden Militar que se tratara. Esta jerarquización hacía a las Órdenes Militares muy poderosas, estando completamente preparadas para batirse en cualquier escenario, fuera Tierra Santa o la propia Península Ibérica durante el largo periodo de la Reconquista; eran básicos la estrategia, el material (armas y armadura) y, cómo no, los caballos. Por otra parte, las comunicaciones entre zonas adscritas, bien fuera en tiempo de guerra como en el de paz, implicaba el control de puertos marítimos y naves en el caso de traslados marítimos, y en el de transporte terrestre, tenemos que señalar como agente esencial al caballo. Las Órdenes Militares debían hacerse con los mejores ejemplares de equinos, es decir, resistentes, dóciles y que se adaptasen sin inconvenientes a un clima semidesértico9. Además debían mantenerlos en las mejores condiciones posibles, ocupándose de que estuvieran alimentados con el mejor forraje y resguardados en buenos establos o en buena cama.

Ciñéndonos al periodo de fundación de las cuatro Órdenes Militares de mayor abolengo en la Península Ibérica durante la Reconquista hemos de decir que la recuperación del extremo sur del Reino de León (también denominado Transierra) fue en gran parte mérito de Alfonso IX de León ${ }^{10}$; este se sirvió de la ayuda de las Órdenes Militares, cuya participación fue clave para la toma de Cáceres (1227), Alcántara, Mérida y Badajoz (1230). A partir de este momento sufren una implementación en cuanto a componentes como a bienes adquiridos, especialmente en la zona extremeña. La Orden de Alcántara reagrupó sus encomiendas en dos regiones, Alcántara y La Serena ${ }^{11}$. La Orden del Hospital aumentó sus terrenos en el priorato de Consuegra; los Templarios ganaron encomiendas en la zona norte y centro de Castilla y de León, llegando hasta la región murciana. Por último, la Orden de Santiago reagrupó sus bienes igualmente en las denominadas "provincia de León" y "provincia de Castilla".

El poder de las Órdenes superaba al poder regio en muchas áreas peninsulares, por eso los monarcas debían colaborar con ellas; un ejemplo de ello se vio durante la Batalla de las Navas de Tolosa, donde Fernando III, "El Santo" hubo de apoyarse en dichas Órdenes y en la nobleza. Alfonso X volvió a colaborar con estas Órdenes para ayudarse en las líneas de defensa fronterizas, las cuales fueron atrayendo multitud de caballeros y nobles en un principio y plebeyos después. El tipo de ganadería que se practicaba aquí se denomina "ganadería de frontera", de carácter extensivo, aprovechando a la vez las tierras (forrajes como la cebada, cereales, vid e higueras), básicas para el mantenimiento de los regimientos, por un lado los caballeros y por otro los animales (caballos y mulos, preferentemente) ${ }^{12}$. De hecho se establecieron hermandades entre pueblos (en especial en la Baja Andalucía) para permitir el pasto, lográndose una exención de impuestos sobre la ganadería y el montazgo ${ }^{13}$, siempre respetando las tierras cultivadas, bajo el auspicio de Alfonso X. Las Órdenes Militares hicieron lo mismo, cooperando la Orden de Calatrava con la de San Juan en 1232 y con la de Santiago en 1239; esta última, a su vez con la de San Juan en 1230. Pese a ello, las Órdenes po- seían pastos restringidos al acceso donde se podía practicar la ganadería, acogiendo ganado trashumante. Las mejores tierras se reservaban a la ganadería extensiva del ganado mayor, bueyes y vacas, mulas y caballos. El resto acogía ganado porcino y pequeños rumiantes. Los comendadores de las Órdenes de filiación cisterciense estaban sujetos desde finales del S. XIII a realizar un inventario anual de caballos, bueyes, vacas, cerdos y borregos, teniéndose constancia de ello en la Orden de Calatrava (1264) y en la de Santiago (1270); es en ésta donde se encuentra la mayor cabaña ganadera de équidos y rumiantes. La localización de los pastos representaba un elemento decisivo para el desarrollo de una Orden Militar, por todos los elementos que ello conlleva en la alimentación del personal y animales, así como el propio terreno en sí, que genera beneficios por su explotación arrendada a terceros.

A lo largo de la Historia de España han surgido diferentes agrupaciones en el seno del Ejército cuya denominación era puesta en honor o como homenaje a ciertos personajes célebres, ciudades o batallas ${ }^{14}$. Además, se les solía colocar un apodo relacionado con su origen o alguna hazaña en la que hubieran tomado parte, como los Regimientos de Infantería "Alcántara" $\mathrm{N}^{\circ} 33$ ("El primero en el peligro") y "Órdenes Militares" $\mathrm{N}^{\circ} 37$ ("El defensor de la Ley y la Fe"). En concordancia con este tema se pueden citar varios regimientos, algunos de ellos desaparecidos o englobados en otras unidades, como el Regimiento de Infantería "Las Navas" No 12, el Regimiento de Infantería "Alcántara" $N^{\circ} 33$, el Regimiento de Infantería "Órdenes Militares" $N^{\circ}$ 37, el Regimiento de Caballería Ligero Acorazado "Santiago" $\mathrm{N}^{\circ}$ 1, el Regimiento de Caballería "Santiago" $\mathrm{N}^{\circ} 2$, el Regimiento de Cazadores "de Santiago" No 9, el Regimiento de Caballería Acorazado "Alcántara" No 10, el Regimiento de Caballería "Alcántara" No 14, el Regimiento de Instrucción "Calatrava" No 2 o el Regimiento de Caballería Acorazado "Montesa" No 3.

En cuanto a la documentación en la que nos hemos basado para este trabajo, aparte de Las Siete Partidas de Alfonso X, "El Sabio", adjuntamos algunas "bulas pontificias" donde se puede apreciar la visión que se tenía en aquella época sobre los caballos y qué importancia les daban. Mediante las "bulas pontificias" se transmitían mandatos, advertencias y decisiones a los maestres de las Órdenes Militares, entre otros, desde la Santa Sede. En ellas se trata de manera sucinta del aprovisionamiento de caballos en la Península Ibérica para combatir contra los musulmanes, principalmente en Tierra Santa. A diferencia de Las Siete Partidas, que están escritas en castellano antiguo (y glosadas en latín), estos otros documentos están completamente en latín, por lo que se adjunta un resumen del texto para facilitar su consulta.

A modo informativo y con relación al apéndice documental, hemos de tratar la fuerte prohibición que impuso el Papa Gregorio IX en 1227 referente a la apropiación de caballos de las Órdenes de San Juan y del Temple por parte de los obispados, ya que estos estaban exentos de tributación eclesiástica, al ser bienes destinados a la defensa de Jerusalén. Hubo donaciones de caballos a esta Orden Militar por parte del Reino de Aragón durante los SS. XII y XIII. Con el Papa Bonifacio VIII se vuelve a recordar la prohibición en 1297. Más adelante se verá que los caballos eran donados de todas las partes de la Península Ibérica, en un principio a estas dos Órdenes; más tarde, con la aparición de las Órdenes Militares estrictamente nacionales continuaron las donaciones a lo largo de 
toda la geografía, predominando Castilla y Aragón. Así, en 1300, Bonifacio VIII concedía mediante otro diploma pontificio el antiguo priorato de San Miguel de Burgo a la Orden de San Juan, donde sus caballos, presumiblemente castellanos, podían aprovechar los excelentes forrajes de la zona. También se debía evitar la venta de caballos hispanos a musulmanes, así como otras armas y similares; una carta escrita desde el Papado en 1234 al arzobispo primado de Toledo le conminaba a no autorizar comercio de caballos u otras mercancías destinadas a la guerra contra los musulmanes. En contraposición, otro diploma que data de cinco años después, donde se comisiona al obispo y al deán de la catedral de Palencia para que autoricen al maestre y a los freiles de la Orden de Santiago para entregar animales de labor a musulmanes a cambio de cautivos cristianos, siempre y cuando no se le entregaran mulas o caballos que pudieran ser usados en la guerra. Algo similar en otro diploma de 1240 donde se le permite al obispado de Mallorca el comercio con musulmanes con la condición de que no fueran caballos o mulos. De todos estos documentos se desprende la gran importancia de los équidos durante las Cruzadas y la Reconquista (vista toda ella como Cruzada), en especial del caballo.

Con respecto a Las Siete Partidas hemos de decir que es un compendio normativo redactado por una comisión formada por los principales juristas castellanos de la época comprendida entre 1256 y 1265, bajo la tutela del monarca Alfonso X, "El Sabio". Entre estos juristas componentes de la cancillería real, estarían el Maestro Jacobo (Jácome Ruiz), el Maestro Roldán, Juan Alfonso (de León) y Fernando de Zamora. Su contenido es principalmente legislativo, aunque a veces puede tener aspectos más filosóficos y literarios. Su aplicación fue a partir de las Cortes de Zamora de 1274, reservándose casi exclusivamente a los casos cuyo conocimiento atañía a la corte real ("pleytos del rey"); los demás casos se tratarían de conformidad con el derecho foral ("pleytos foreros").

La principal finalidad de este código legal se cree que fue para ser aplicado a todo el Imperio, como norma jurídica compilatoria compartida, en relación con el denominado "fecho del imperio" (intento del monarca Alfonso X, "El Sabio", para conseguir la corona del Sacro Imperio Romano-Germánico). Un hecho muy reseñable es que fueran redactadas en castellano en lugar de estar en latín. Por todo ello se considera a Las Siete Partidas como un hecho unificador para todo el territorio que poseyera el rey. Tuvo vigencia no sólo jurídica, sino moral, durante toda la Baja Edad Media.

\section{EL CABALLERO Y LOS CABALLOS}

El binomio hombre - caballo ha existido desde la antigüedad. Al principio con unos fines enfocados hacia la agricultura o el alimento, luego como ayuda para el transporte; finalmente, arma efectiva para conseguir avances y retiradas en las guerras, así como por su velocidad y resistencia. Las primeras dataciones en cuanto al uso del caballo con fines agrícolas y de transporte son de hace más de 8000 años, aunque muy anteriormente las tribus nómadas de las regiones del Caspio ya los usaban de manera más sucinta $^{15}$. Es a partir del 6000 a. C. cuando surgen arreos, guarniciones y aperos para los équidos en general; es este momento cuando comienza la idea de selección para la mejora caballar y se desarrolla el arte de la monta.
La caballería comenzó a generalizarse en multitud de ejércitos; aquéllos que en un principio lo dejaron de lado se arrepintieron rápidamente. Más adelante se llegaron a promulgar leyes que favorecían la cría caballar. Un ejemplo claro son los Reinos de la Península Ibérica, durante la Reconquista; estaba terminantemente prohibido sacar caballos fuera del Reino, bajo pena de confiscación de bienes o incluso la pena de muerte ${ }^{16}$. Los testimonios de esta interrelación entre el hombre y el caballo que, a medida que avanza el tiempo, se convierte en caballero - caballo, son múltiples, la mayoría representaciones artísticas. De hecho, ser caballero era una distinción que no sólo implicaba saber montar a caballo, estaba (y está) unida al comportamiento, el oficio o la procedencia, como si se tratara de un caballo distinguido o no.

A la vez que las ya citadas representaciones, nos han llegado hasta la actualidad dichos o frases que hacen patente este binomio, como "a caballo regalado, no le mires el diente", "caballo de batalla", "a caballo entre...", "cola de caballo", "a uña de caba1lo...", etc. Al igual, la introducción del caballo en otros campos, como en el ajedrez, en la baraja española, en la denominación de otros animales ("caballo del diablo", "caballo de mar"), o como símil en vehículos a motor ("caballo de vapor").

\section{LAS SIETE PARTIDAS}

\section{TÍTULO. XXI. De los caualleros, e de las cosas que les conuiene fazer}

En la Segunda Partida, dentro del Título XXI, podemos ver diferentes apartados, organizados en leyes, donde se explica el concepto de caballero y todas las consecuencias que ello implica. Como está escrito en castellano antiguo citaremos las referencias en castellano actual, estando el texto completo incluido en el apéndice documental.

Previamente señala a los caballeros como personas escogidas, “(... a quien los antiguos dice defensores. Lo uno porque son más honrados. Lo otro porque señaladamente están establecidos para defender la tierra y acrecentarla (...)". Esto es porque "en defender yacen tres cosas: esfuerzo y honra y poderío."

\section{+ Ley. I. Por que razones la caualleria e los caualleros ouieron assi nome}

"La caballería fue llamada antiguamente la compaña de los hombres nobles, que fueron puestos para defender las tierras. Y por ello le pusieron nombre en latín militia: que quiere tanto decir, como compañas de hombres duros y fuertes, y escogidos, para sufrir trabajo y mal, trabajando, y padeciendo, por el pro de todos comunalmente. (...) de mil hombres se escogía uno para hacerse caballero.” De aquí se desprende que un caballero tenía una muy alta reputación y era difícil llegar a serlo. Debía poner su vida al servicio de los demás. Pero la denominación proviene en un principio de caballo, ya que solían ir montados a caballo: "(...) como los que andan a caballo, van más honradamente que en otra bestia.” Al ser escogidos, son más honrados, por lo que el animal más indicado sobre el que deben ir montados es el caballo, la "bestia" más honrada del mundo animal. Pero un caballero es más que eso: "Mas en España, llaman caballería, no por razón que andan cabalgando en caballos, 


\section{Los caballos y las Órdenes de Caballería: una visión a través de Las Siete Partidas de Alfonso X...}

(...) así como el nombre de la caballería, fue tomado de compaña de hombres escogidos para defender, además fue tomado el nombre de caballero de la caballería". Como consecuencia, caballo, caballero y caballería son tres conceptos que deben estar unidos, representado valía, honra y exclusividad, entre otras muchas virtudes.

\section{+ Ley. II. Como deuen ser escogidos los caballeros}

Como ya se menciona en la anterior ley, un caballero se obtiene de entre mil, de ahí la palabra "militia”, “(...) así entre los centenarios, es el mayor mil: porque todos los otros se encierran en él. (...) Y por esta razón escogían antiguamente de mil hombres uno, para hacerle caballero (...)". A la hora de escoger a los futuros caballeros se pedían tres cosas: "La primera que fuesen lazradores, para sufrir la gran lazería, y los trabajos que en las guerras, y en la lides les acaeciesen. La segunda que solieran herir (...). La tercera, que fuesen crudos para no tener piedad, de robar lo de los enemigos, ni de herir, ni de matar, ni además que no se desmayen por golpe que ellos recibiesen, ni que diesen a otros." Como se ve, los caballeros debían ser entregados a su trabajo y con gran fortaleza, que no cesaran fácilmente en su tarea por muy cruda que fuera. Así relata los más idóneos para el puesto: “(...) los venadores del monte, que son hombres, que sufren gran lazería, y carpinteros, y herreros, y pedreros, porque suelen herir y son fuertes con las manos. $Y$ además los carniceros, por razón que suelen matar las cosas vivas, y esparcir la sangre de ellas." Además de tener estos oficios, los hombres debían ser "(...) bien faccionados de miembros, para ser recios, y fuertes y ligeros." De hecho también se nombra una frase de Vegecio hablando de la Orden de Caballería: "que la vergüenza impide al caballero que no huya de la batalla, y por ello le hace vencer". Se intentó que los caballeros provinieran de un buen linaje, para que evitaran hacer cosas que les pudieran hacer caer en vergüenza, tanto a su persona como a todo el linaje, posteriormente: "Y porque estos fueron escogidos de buenos lugares, y con algo, que quiere tanto decir en lenguaje de España como bien, por ello los llamaron hijos dalgo, que muestra tanto como hijos de bien. Y en algunos otros lugares los llamaron gentiles. Y tomaron este nombre de gentileza, que muestra tanto como nobleza de bondad, porque los gentiles fueron hombres nobles y bueno, y vivieron más ordenadamente que las otras gentes." La denominada gentileza podía ser por linaje, por saber (sabiduría) y por bondad de costumbres y maneras (modales). Asimismo dice que “(...) estos que lo ganan por sabiduría, y por su bondad, son por derecho llamados nobles y gentiles mayormente (...)”. Como anteriormente decíamos, la vergüenza puede ser pasada al resto del linaje: "Porque no tan sólo, cuando lo hacen, reciben daño, y vergüenza ellos mismos, mas aquéllos de donde vienen." Los hijosdalgo pueden heredarlo hasta desde el cuarto grado, desde los bisabuelos.

\section{+ Ley. III. Como los fijos dalgo deuen guardar la nobleza, e la fidalguía}

La hidalguía es "nobleza que viene a los hombres por linaje". Por ello, los hijosdalgo deben conservarla e implementarla, evitando así que se acabe en ellos, debido a algún error grave o por caer en vergüenza. A la hora de nacer, aunque es más importante el padre porque "siempre los hombres el nombre del padre ponen primeramente delante, cuando alguna cosas quieren decir", la ma- dre también tiene otro hueco relevante, y el hijo es consecuencia de los dos. Y como se sabe, el hijo nace y luego se hace, es decir, aunque tenga linaje, debe ser entendido (sabiduría) y tener buenos modales y costumbres.

\section{+ Ley. IIII. Como los caualleros deuen auer en quatro virtutes principales}

En los caballeros deben existir cuatro bondades o buenas costumbres, denominadas en latín virtudes, “(...) así como cordura, y fortaleza, y mesura, y justicia”. La primera implica que los caballeros obren teniendo en cuenta las consecuencias; la segunda para que "estén firmes en lo que hicieren, y no sean cambiadizos. Y la mesura que obren de las cosas como deben (...). Y la justicia, que la hagan derechamente." Por esto y de modo paralelo, desde antiguo se hacen armas de cuatro maneras: "Las unas que vistan y calcen. Las otras que ciñan. Las otras que se ponen ante sí. Las otras con que se hiera." Todas ellas se simplifican en dos: "Las unas para defender el cuerpo, que son llamadas armaduras. Las otras armas que son para herir." Todas estas virtudes están englobadas dentro del concepto de ESPADA. Las "armas" que el caballero utiliza como vestimenta de defensa muestran la "cordura, que es virtud que le guarda de todos los males que le podrían venir por su culpa bien así muestra eso mismo el mango de la espada (...)", mientras que las armas que tiene consigo para defenderse muestran "fortaleza, que es virtud que hace al hombre estar firme ante los peligros que hubiere (...). Y bien como las armaduras que el hombre ciñe, son medianeras entre las armaduras que se viste y las armas con que hiere, y son así como virtud de la mesura, entre las cosas que se hace además, o de menos, de lo que deben, bien a esa semejanza es puesto el arrias entre el mango y el hierro de ella". Por último, las armas que el caballero tiene "enderezadas" en disposición de ataque "muestran justicia, que ha en sí derecho e igualdad, eso mismo muestra el hierro de la espada, que es derecho y agudo, y está igualmente de ambas partes. Y por todas estas razones, establecieron los antiguos, que las trajeran siempre consigo los nobles defensores, y que con ellas recibiesen honra de caballería."

\section{+Ley. V. Que los defensores deuen ser entendidos}

Además de las cuatro virtudes descritas anteriormente, al caballero hay que añadirle que sea "entendido", esto es "la cosa del mundo, que más endereza al hombre para ser cumplido en sus hechos, y que más le diferencia de las otras criaturas, y por ello los caballeros que han de defender así, y a los otros según lo dicho, deben ser entendidos." De lo contrario errarían en las cosas que hicieran, ya que "el desentendimiento, les haría que no mostrasen su poder (...)". El desentendimiento haría que no fueran consecuentes en sus acciones, inclinándoles hacia la crueldad, en lugar de ser piadosos, desleales en lugar de leales, flacos en sus acciones en vez de esforzados, o codiciosos en lugar de renunciar a favor de sí mismos.

+ Ley. VI. Que los caualleros deuen ser sabidores para saber obrar de su entendimiento

Junto con el entendimiento, "debe haber poder para defender, si sabiduría no hubiese para saber lo que hacer, no les valdría nada, 
porque la obra aduce al hombre a acabamiento de lo que entiende, y es así como espejo en el que se muestra su voluntad, y su poder (...)". Por ello deben aunar la sabiduría para actuar como buenos defensores cumpliendo con su deber.

\section{+ Ley. VII. Que los caualleros deuen ser bien acostumbrados}

Para llegar a ser caballero hay que cumplir una larga serie de requisitos, nunca llegando a ser soberbios ni altivos, sino humildes "para halagar y llegar a aquéllos que con ellos fuere (...)", siendo bravos y fuertes cuando la situación lo requiera, con palabras o con hechos, "para espantar los enemigos (...)”. Los caballeros deben estar acostumbrados, es decir, saber cómo actuar en cada momento.

\section{+ Ley. VIII. Como deuen los caualleros ser arteros e maňosos}

Para el desempeño de su trabajo es conveniente que sean astutos, buscando siempre atajos o caminos más cortos hacia un fin común: "porque bien así como las mañas les hacen sabedores de aquello que han de hacer por sus manos, la astucia hace buscar caminos para saber acabar mejor (...)". Las mañas les hacen saber defenderse con mayor eficacia, "y herir con toda arma, y ser bien ligeros y buenos cabalgantes." La astucia les ayuda a "vencer con pocos, a muchos (...)", saliendo mejor de los peligros en los que pudieran caer.

\section{+ Ley. IX. Como deuen ser los caualleros muy leales}

Pero la "madre" de todas las buenas costumbres o virtudes debe ser la lealtad. Todos los caballeros la deben cumplir por tres razones: "La primera es porque son puestos por guarda, y defensa de todos, y no podrían ser buenos guardas lo que leales no fuesen. La segunda por guardar honra de su linaje lo que no guardaría cuando en lealtad errasen. La tercera por no hacer ellos cosa porque cayeran en vergüenza en lo que caerían, mas que por otra cosa, si leales no fuesen". Deben intentar cumplir con su deber evitando dañar o meter en peligro a aquéllos que no se lo merezcan, siendo siempre leales con su señor, incluso yendo contra su voluntad.

+ Ley. X. Que los caualleros deuen ser sabidores para conoscer los cauallos, e las armas que traxieren si son buenos o non

En las anteriores leyes se ha visto cómo debe ser un caballero y el uso que debe dar a sus armas; el caballo es su mejor arma, con él se puede trasladar, puede transportar material, es un compañero de viaje, es un arma veloz, resistente y efectiva en la guerra, sin olvidarnos que le proporciona una posición más honrosa y mayor visión durante la batalla y fuera de ella. El caballero no debe descuidar sus armas, ya que sin ellas perdería una protección vital: "Caballos y armaduras y armas son cosas que conviene mucho a los caballeros poseerlas buenas, cada una según su natura. Porque con éstos han de hacer los hechos de armas, que es su menester, conviene que sean tales que se puedan bien ayudar." El caballo es el arma más importante; no valía cualquier tipo de caballo, se le pedían unas cualidades que deducimos más adelante, ya que "Ésta es la más señalada cosa en conocer el caballo. Porque por ser el caballo más grande, y hermoso, si fuese de malas costumbres, y el caballero no fuese sabedor para conocer esto, tendría dos males: Lo uno que perdería cuanto por él diese. Y lo otro, que podría por él caer, en peligro de muerte, o de ocasión. Y esto mismo le ocurriría, si no fuesen las armaduras buenas, y bien hechas (...)’. El caballero debe conocer a la perfección su caballo, deben formar una única entidad, consolidando el binomio caballero - caballo. Es preferible que sea un caballo menos corpulento y menos bello, pero que tenga una sintonía perfecta con su amo y que haya reciprocidad.

Se les pedían tres cosas a los caballos: "La primera, ser de buen color. La segunda, de buenos corazones. La tercera, tener miembros convenientes, que respondan a estos dos. Y aún sobre todo esto, quien bien los quisiere conocer, ha de catar que vengan de buen linaje. Porque esta es la animalia del mundo que más responde a su natura". Aparte de las características morfológicas menos relevantes (capa), debe tener buenos aplomos (esto es fundamental para evitar enfermedades subsecuentes), y deben mostrar arrojo y valentía. Ya en Las Siete Partidas aparece el concepto de pedigrí comentando que, si provienen de un buen linaje cumplirán lo que se les presupone, estableciendo un paralelismo con el caso de los hijosdalgo.

Los caballeros tenían que cuidar de sus caballos y, para ello hay "tres cosas, para hacer buenos los caballos. La primera, mantenerlos en sus bondades. La segunda, si alguna mala costumbre tuvieren, quitarlos de ella. La tercera, protegerlos de las enfermedades que tuviesen (...)" o pudieran tener, de ahí los cuidados que precisan. El animal se comportará de igual manera que el caballero se comporte con él. A medida que el caballero coja experiencia realizará mejor su tarea y usará mejor sus armas, entendiendo en este punto como arma al propio caballo.

Los caballeros de los ejércitos cristianos montaban "a la brida" (estribos largos, piernas rectas apoyadas en los estribos) en contraposición a los moros, que iban "a la jineta" (estribos cortos, piernas anguladas, y silla y frenos más livianos) ${ }^{17}$. Asimismo, mientras que los cristianos estaban completamente vestidos con las armaduras, los moros iban más ligeros. Esto, lógicamente estaba relacionado con el tipo de caballos, siendo en el lado cristiano más grandes y fuertes (como el caballo castellano-leonés), y en el otro bando más ligeros y rápidos (como el caballo andalusí). Según avanzaba la contienda en la Península Ibérica, a favor de los reinos cristianos, éstos fueron adaptándose a otros tipos de caballos más ligeros, asimilando la monta "a la jineta".

\section{+ Ley. XI. Quien ha poder de fazer los caualleros o non}

Como es de suponer deben ser nombrados caballeros por otros que también lo sean: "Hechos no pueden ser los caballeros, por mano de hombre, que caballero no sea (...) ninguno no puede ser caballero de mano del que no lo fuere”. Las Órdenes de Caballería tenían tanto abolengo que: "Y tanto encarecieron los antiguos la orden de caballería, que tuvieron que los Emperadores, ni los Reyes, no deben ser consagrados, ni coronados, hasta que caballeros fuesen. Y aún dijeron más, que ninguno no puede hacer caballero, a sí mismo, por honra que tuviese". Debe "darle" ese premio, el de ser caballero, otro que así lo sea: "Y por ello, ha menester, que en la caballería haya dos personas, aquél que la da, y el que la recibe”. La caballería era un estatus al que pocos podían aspirar, aun cuando tuvieran méritos, se necesitaba un "padrino" de ceremonias caballero: "porque la caballería es tan noble, y tan honrada, que debe 


\section{Los caballos y las Órdenes de Caballería: una visión a través de Las Siete Partidas de Alfonso X...}

entender el que la da, que es lo que hace en darla, lo que estos no podrían hacer". Ya de aquélla existían problemas de competencias en este sentido con las mujeres y con los clérigos, a los que se intentaba tener al margen, "porque sería cosa, muy sin razón, de entremeterse de hecho de caballería, aquéllos que no quieren, ni han poder, de meter y las manos, para obrar de ella." Aunque dejaba las puertas entreabiertas a clérigos que hubieran sido caballeros antes de entrar en la Iglesia: "Pero si alguno fuese caballero primeramente, y después le acaeciese, que quisiese ser maestro de orden de caballería, que mantuviese el hecho de armas, no fue tal como éste, defendido de poderlo hacer."

\section{+ Ley. XII. Quales non deuen ser caualleros}

Se establecen dos caminos en los que no se cumplen las expectativas para ser caballero, por un lado de hecho, la otra por razón. "En la de hecho, es cuando los hombres no han cumplido lo que ha menester (...) por razón es cuando no tienen derecho, porque las deban hacer." Es decir, a causa de las acciones que hayan hecho previamente o por otras transversales, como ser clérigo, por la edad que posean, por ser muy pobre, etc. Como ya se indicaba, el caballero es escogido, a la caballería no pueden acceder hombres con el fin de mendigar en ella, o deshonrarla, hurtar o incluso utilizarla como un negocio; también se establecen límites de carácter físico, locos o minusválidos tampoco podían serlo: "no debe ser hecho caballero, el que fuese menguado, de su persona, o de sus miembros, de manera que no pudiese en la guerra ayudar con las armas." Al igual que ocurre en la actualidad en las pruebas de acceso a las funciones públicas y estableciendo una analogía, no debía hacerse caballero "al que fuese conocidamente traidor, (...) o dado, por juicio por tal, ni hombre que fuese juzgado para muerte, por errores que hubiese hecho, si primero no hubiese sido perdonado, no tan sólo la pena mas aún la culpa." Además se contemplaban acciones contra aquéllos que hubieran mentido previamente o hubieran sido hechos caballeros de manera incorrecta. El ser caballero es un honor que no se paga con dinero, "así como el linaje no se puede comprar, además la honra, que viene por nobleza, no la puede la persona tener, si ella no fuere a tal, que la merezca por linaje, o por seso, o por bondad que haya en sí."

\section{+ Ley. XIII. Que cosa deue fazer el escudero ante que reciba caualleria}

El escudero es otra pieza básica, principalmente en la limpieza del caballo y el aseo del caballero. En el caso del caballero, él es quien tiene que fomentar e incrementar su limpieza interior: "en sus bondades, y en sus costumbres (...).” Pero la parte externa es encargada al escudero: "en sus vestiduras, y en las armas que trajere.” Esto le ayudará al caballero a sentirse más cómodo en los hechos de armas. Ya se sabe que la apariencia externa es muy importante y suele mostrar cómo es la persona por dentro. El escudero debía ser "de noble linaje”, y, el día antes de que sea nombrado caballero su señor, debe guardar vigilia; además, "han los escuderos de bañar, y lavar su cabeza, con sus manos, y echarle en el más apuesto lecho, que pudiera haber. Y alli le han de vestir, y de calzar a los caballeros, de los mejores paños, que tuvieren." Hecho todo este ritual, el caballero se limpiaría por dentro yendo a la iglesia acompañado por su escudero, velando y pidiendo para cumplir con sus futuras obligaciones dentro de la Orden de la que va a ser partícipe. La vigilia de los caballeros "no fue establecida, para juegos, ni para otras cosas, sino para rogar a Dios (...).” El escudero es ayudante de ceremonias antes de la obligada vigilia.

\section{+ Ley. XIIII. Como hă de ser fechos los caualleros}

Anteriormente se trata la ESPADA como el arma que posee las cuatro virtudes que debe tener el caballero, por ello es el elemento a utilizar durante su nombramiento como caballero tras la vigilia y la misa. "Si dijere sí, le ha de preguntar, si la mantendría, así como se debe mantener, y después que se lo otorgare, debe calzarle las espuelas, o mandar a algún caballero que se las calce (...) así como el caballero pone las espuelas de diestro, y de siniestro, para hacer correr al caballos derecho, que así debe hacer derechamente sus hechos de manera que no tuerza a ninguna parte." Luego ha de ceñir la espada. Hay que resaltar que los que iban a ser nombrados caballeros solían ir vestidos completamente con su armadura y con la cabeza descubierta, ya que si se tenía cubierta se pensaba que estaba encubriendo alguna cosa o por algún motivo del que estuviera avergonzado, "Por eso han de recibir, tan noble, y tan honrada cosa, como la caballería, no es derecho que entren en ella, con mala vergüenza, ni con miedo. Y desde que la espada la hubieren ceñido, debe desenvainarla, y ponérsela en la mano derecha, y hacer el juramento, estas tres cosas. La primera que no recele de morir por su ley, si fuere menester. La segunda por su Señor natural. La tercera por su tierra. Y cuando esto fuere jurado, debe dar una estocada (...)." A partir de este momento forma parte de la hermandad de caballeros de la Orden de Caballería.

\section{+ Ley. XV. Como han de desceñir la espada al nouel, despues que fuere fecho cauallero}

La persona que lo nombre caballero será su propio señor $\mathrm{u}$ otro caballero u hombre "honrado que lo hiciese por favor, que tuviese que hacerle honra, o caballero que fuese muy bueno de armas, que lo hiciese, por su bondad." Es muy importante esta ceremonia porque sirve de punto de partida en la vida de un caballero y siempre se tendrá en cuenta. El encargado de desceñirle la espada es el "padrino", que "con su mano otorga, y confirma la caballería que ha recibido."

\section{+ Ley. XVI. Que debdo han los noueles cŏ los que los fazen caualleros, e cŏ los padrinos que los desciñen las espadas}

La deuda que contrae el caballero no es sólo con los que los nombran caballeros, sino con sus "padrinos" encargados de desceñirles las espadas. Por ellos se estableció "que el caballero, nunca fuese contra aquél de quien hubiese recibido caballería.” Incluso establecieron que, en el caso de estar enfrentados su señor con su "padrino" se abstuviese en un principio. Lo que estaba claro era que les debían lealtad a ambos, evitando hacerles cualquier daño o herirlos, especialmente a su Señor.

\section{+ Ley. XVII. Que cosa deuen guardar los caualleros quando caualgaren}

Las buenas maneras que debe tener un caballero se plasman en todos los ámbitos, desde comer, beber, vestir, dormir, y cómo no, 
cabalgar. Al ir montados a caballo "van en ellos más honrados, que en ninguna otra cabalgadura. Y además, porque usasen el cabalgar, que es cosa que pertenece mucho a los caballeros, y porque andar en los caballos, mas lozanos, y más alegres (...) que cuando fuesen a cabalgar, fuera de villa, en tiempo de guerra, que fuesen en sus caballos armados, de manera que si acaeciese pudiesen hacer daño a sus enemigos, y guardarse de recibirlo de ellos." También se aconsejaba que cabalgasen solos, porque de lo contrario podrían torcer la vista y distraerse de sus acciones. Señala que la espada fuera ceñida mientras cabalgaran, ya que era el hábito de la caballería.

\section{+ Ley. XVIII. En que manera se deuen vestir los caualleros}

Como es sabido, era muy importante la apariencia de los caballeros y sus caballos, por ello se esmeraban mucho a la hora de vestirlos y vestirse (con la ayuda de sus escuderos): "Paños de colores establecieron los antiguos que trajesen vestidos, los caballeros nobles mientras que fuesen mancebos, así como bermejos, y jaldes, y verdes, o cárdenos, para que les diesen alegría. Mas prieto, o pardo, o de otro color, que sea que les hiciese entristecer, no tuvieron por bien que los vistiesen." Los colores más llamativos les hacían estar más alegres y acrecentar sus corazones, de modo que combatieran mejor y se esforzaran más en su cometido. Ocurría igual con los caballos, que iban a juego con sus jinetes; los mantos "los hacían grandes y luengos, que les cubriesen hasta los pies, y sobraba tanto paño, de una parte, como de la otra, sobre el hombro derecho (...)", de este modo podían esconder su cabeza bajo ese hombro en algunas situaciones de peligro. Se le denominaba a esta vestimenta "manto caballeroso", y tenía un doble fin, ya que era similar al que llevan los clérigos, y les "ata" a su juramento y les supone humildad. Lo llevaban siempre, mientras comían o cabalgaban, siendo el escudero el encargado de mantenerlo siempre limpio.

" $Y$ esto mismo establecieron de las armaduras, como de las otras armas, que trajesen, que fuesen hermosas, y muy apuestas.”

\section{+ Ley. XIX. Como los caualleros deuen ser mesurados}

En esta ley se trata el modo de actuación de los caballeros con respecto al comer, beber y dormir: "deben usar en tres maneras. La una con tiempo. La otra con mesura. La otra apuestamente." Dependiendo de si había guerra o no se hacían las comidas a distinta hora y el menú era también diferente (evitar sobrecargar el estómago durante la guerra y que no hubiera deshidratación). Igualmente ocurría con el tipo de bebida que ingerían, ya que el alcohol podía desconcentrar en un momento crucial, " $Y$ cuando había grandes calenturas, les daban un poco de vinagre, con mucha agua, para que les quitase la sed (...).” Lo que sí estaba claro era que las tres acciones eran esenciales para mantener una forma física y saludable de cara a desempeñar cualquier función, bien fuera en tiempo de paz o de guerra, aunque se les solía acostumbrar a que durmieran poco (y con vestimenta cómoda), ya que los principales eventos durante una batalla ocurren por la noche o al alba.

\section{+ Ley. XX. Como ante los caualleros deuě leer las estorias de los grandes fechos de armas quando comieren}

La sabiduría se puede obtener por el método tradicional y de modo empírico, y así estaba escrito que hicieran los caballeros: "así como en tiempo de guerra aprendiesen hechos de armas, por vista o por prueba, que además en tiempo de paz lo hiciesen por oídas, por entendimiento.” El momento idóneo para aprender es en el que se juntan todos, es decir, a las horas de comer, es ahí cuando los caballeros más experimentados pueden contar sus anécdotas y los noveles aprender de ellos, "Y por ello acostumbraban los caballeros, cuando comían, que les leyesen las historias de los grandes hechos, de armas que los otros hicieran (...)." Por eso no se consentía durante las comidas que, en el caso de haber juglares para amenizarlas, éstos "dijesen ante ellos otros cantares, si no de guerra, o que hablasen de hechos de armas". Los caballeros escuchaban las historias y "les crecían las voluntades, y los corazones, y se esforzaban, haciendo bien, y queriendo llegar, a lo que los otros hicieran, o pasaran por ellos."

\section{+ Ley. XXI. Que cosas son tenudos los caualleros de guardar}

Esta ley se refiere a que lo que los caballeros juran en su ordenación deben cumplirlo, entre ellas cumplir con su tarea, defender por todos los medios a su señor (acrecentando su tierra y su honra). "Y porque fuesen tenidos de guardar esto, y no errar en ello, de ninguna manera, les hacían antiguamente dos cosas. La una que los señalaban en los brazos derechos, con hierros calientes de señal, que ningún otro hombre no la había de traer, si no ellos. Y la otra que escribían sus nombres, y el linaje de donde venían, y los lugares de donde eran naturales, en el libro donde estaban escritos todos los nombres de los otros caballeros." De esta manera, cuando fallasen en su empeño serían reconocidos y recibirían la pena que fuera oportuna por ello. Debían tener mucho esmero a la hora de llevar a cabo su trabajo y ayudar al resto de la gente, así como sus propios bienes y armas: "guardar todas cosas, que derechamente les eran dadas en encomienda, defendiéndolas así como lo suyo. En fin todo esto, guardaban, que caballos, ni armas, que son cosas que conviene mucho a los caballeros traerlas siempre consigo, que no las empeñasen, ni las mal vendiesen, sin mandato de sus Señores (...).” Y lógicamente estaba prohibido que un caballero cometiera delitos de la índole de hurtos u otros engaños similares, " $Y$ entre todos los hurtos, señaladamente en los caballos, y en las armas de sus compañeros, cuando estuviesen en hueste."

\section{+ Ley. XXII. Que cosas deuen fazer, e guardar los caualleros, en dichos e en fechos}

Existen dos cosas que los caballeros nunca deben dejar de hacer, "Las unas en dicho. Las otras en hecho. Y las de palabras son que no sean villanos, ni desmesurados en lo que dijeren, ni soberbios, si no en aquellos lugares donde les conviene así como en hecho de armas, donde han de esforzarse los suyos, y darles voluntad de hacer bien (...)." El caballero debe cumplir su palabra y animar a sus "hermanos" a hacer lo mismo; pueden mentir en el caso de que haya alguna buena acción consecuente con ella: "(...) en aquellas cosas, que se fuese a tornar la mentira en algún gran bien, así como desviando daño, que podría acaecer, si no mintiesen." También si con esa mentira se calmaran los ánimos durante alguna situación difícil. Pero no deben nunca contradecir su juramento ni dejar de ser leales y firmes en sus convicciones contraídas, ya que "la lealtad les hará guardarse de yerro, y la firmeza hará que no sean movedizos de una cosa a la otra, que es algo que no conviene 


\section{Los caballos y las Órdenes de Caballería: una visión a través de Las Siete Partidas de Alfonso X...}

a los defensores"; todo ello sin descuidar su apariencia externa (armaduras y su propio caballo fundamentalmente). La maña y la astucia no están reñidas con todas las bondades anteriormente mencionadas.

\section{+ Ley. XXIII. En que manera deuen honrrar los caualleros}

Los caballeros deben ser muy honrados por tres razones fundamentales: "La una por nobleza de su linaje. La otra por su bondad. La tercera por el pro que de ellos viene. Y por tanto los Reyes los deben honrar como aquéllos con quien han de hacer su obra, guardando y honrando asimismo con ellos, y acrecentando su poder y su honra. Y todos los otros comunalmente los deben honrar (...)." Los caballeros son defensores y protectores, y así como ellos respetan y defienden, así deben ser ellos mismos tratados por sus superiores y el resto del pueblo. Tenían bastantes prerrogativas, por ejemplo "ninguno debe estar en la iglesia ante ellos, cuando estuviesen a las horas, sino los prelados, o los otros clérigos que las dijesen, o los Reyes, o los grandes Señores, a quien ellos hubiesen de obedecer y de servir." Igualmente ocurriría en el momento de sentarse a comer a la mesa o dirigirles la palabra, sólo con los de su mismo rango o estatus. "Ni les deben además prender los caballos, ni las armas fallándoles alguna otra cosa (...), no les deben tomar los caballos de sus cuerpos, ni descenderlos de las otras bestias, en que cabalgasen (...)." De hecho, para poder llegar a ser Rey o Emperador una persona debía ser antes caballero, al igual que para llegar a obispo antes tendría que haber hecho los votos.

\section{+ Ley. XXIIII. Que mejoría han los caualleros apartadamente mas que los otros omes}

Además de las prerrogativas enunciadas anteriormente, los caballeros tenían más ventajas por el mero hecho de serlo, especialmente de cara a posponer juicios o tener un trato mejor que cualquier otra persona del pueblo. En un caso muy grave "no le deben dar una muerte vil, así como arrastrándolo, o enforcándolo, o destripándolo. Mas han de decapitarlo por derecho, o matarlo de hambre, cuando quisiesen mostrar, contra él, gran crudeza, por algún mal que hubiese hecho." En España, los caballeros que hurtaban, o robaban cosa ajena, o traicionaban, eran despeñados desde un lugar alto y así se desmembraban o ahogaban en el mar. Otro beneficio que tenían era que, mientras estaban desempeñando su cargo y les ocurría algo a sus mujeres o sus propiedades, podían pedir su restitución o arreglo, ya que estaban cumpliendo con sus obligaciones para con el Rey o sus señores, aunque había unos plazos para pedirlo.

\section{+ Ley. XXV. Por quales razones pierden los caualleros honrra de la caualleria}

Lo peor que le puede ocurrir a un caballero es perder la honra de la caballería. Esto podía ocurrir de dos maneras: "La una cuando les quitasen tan sólo orden de caballería, y no les dan otra pena en los cuerpos. Y la otra, cuando hacen tales yerros, por los que merecen la muerte." Los yerros podían ocurrir cuando, en el pleno ejercicio de su trabajo "vendiese, o mal vendiese el caballo, o las armas, las perdiese a los dados o las diese a las malas mujeres, o las empeñase en la taberna, o hurtase, o hiciese hurtar a sus compañeros las suyas, o si a sabiendas hicieses caballero, a hombre que no debiese serlo, o si usase públicamente él mismo de contrabando, u obrase de algún vil menester de manos, por ganar dineros (...)." Estos motivos son graves, al igual que desertar, especialmente en tiempo de guerra, desamparar a su señor, a la encomienda que le fuera encargada, si no le diesen su propio caballo al señor, por traición, etc. El modo de ser expulsados de la caballería era "que debe mandar el Rey, a un escudero, que le calce las espuelas, y le cinche la espada, y que le corte con un cuchillo la cinta de la parte de las espadas, y además que taje las correas de las espuelas, teniéndolas calzadas." Después de esto no puede ni debe ser llamado caballero, perdiendo la honra y sus privilegios, no pudiendo ser recibido en ningún oficio del Rey, ni podrá acusar a otro caballero.

\section{AGRADECIMIENTOS}

Este trabajo fue galardonado en su extensión con la $10^{\mathrm{a}}$ edición del premio "Veterinaria Militar, General Sobreviela Monleón” (Madrid, 2009).

\section{BIBLIOGRAFÍA}

1. Gual Camarena M. Alfonso X de Castilla y León, el Sabio. Madrid: Editorial Rialp, 1971.

2. Alfonso X, "El Sabio". Las Siete Partidas (Glosadas por el Lcdo. Gregorio López). Salamanca: 1555.

3. Gual Camarena M. Op. cit.

4. Torres Sevilla M. (Coord.). Las Órdenes Militares: un puntal de la historia de Occidente. Soria: Ediciones Cátedra Internacional Alfonso VIII, 2006.

5. Domínguez Sánchez S, Martínez Pérez JM. Los caballos hispanos en el S. XIII y su presencia en las cruzadas. Actas XXXVII Congreso Internacional de la Asociación Mundial de Historia de la Veterinaria y XII Congreso Nacional de Historia de la Veterinaria. León: Editorial MIC, 2006.

6. Cuesta, JI. Breve historia de las Cruzadas. Madrid: Editorial Nowtilus, 2005.

7. Lewis, FE. Historia de los caballeros templarios. Barcelona: Editorial Obelisco, 2004.

8. Torres Sevilla M. Op. cit.

9. Domínguez Sánchez S, Martínez Pérez JM. Op. cit.

10. Torres Sevilla M. Op. cit.

11. Pastor de Togneri R. Resistencia y luchas campesinas en la época del cimiento y consolidación de la formación feudal. Castilla y León, SS. X-XIII. Madrid: 1980.

12. Gerbet MC. La ganadería medieval en la Península Ibérica. Barcelona: Editorial Crítica, 2003.

13. Domínguez Sánchez S, Martínez Pérez JM. Op. cit.

14. Lión Valderrábano R, Silvela Milans del Bosch JM. La Caballería en la Historia Militar. Valladolid: Ediciones Academia de Caballería, 1979.

15. Abad Gavín M. El Caballo en la Historia de España. León: Servicio de Publicaciones de la Universidad de León, 1999.

16. Domínguez Sánchez S, Martínez Pérez JM. Op. cit.

17. Abad Gavín M. Op. cit. 